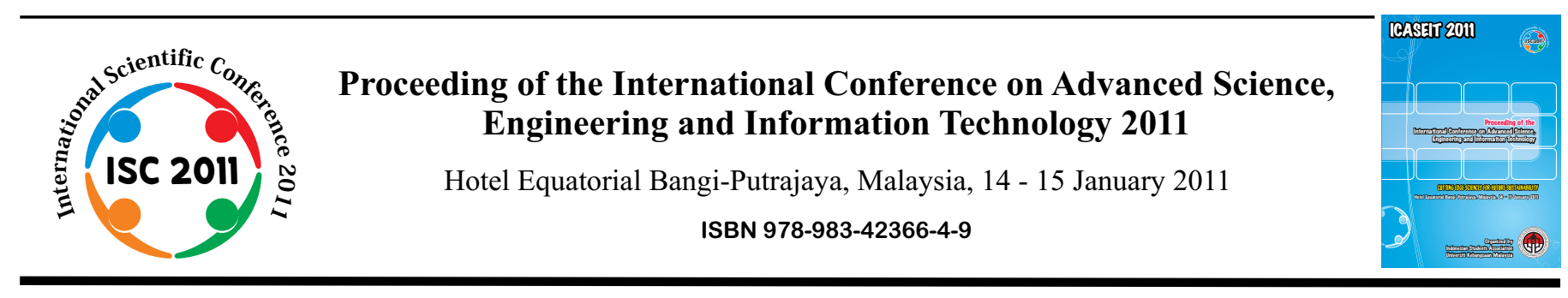

\title{
Microwave Assisted Hot Air Convective Dehydration of Fish Slice: Drying Characteristics, Energy Aspects and Colour Assessment
}

\author{
Mohd Rozainee T. ${ }^{\#}, \mathrm{Ng}$ P. S. \\ * Faculty of Chemical Engineering, Universiti Teknologi Malaysia, 81310,UTM Skudai, Johor, Malaysia. \\ E-mail: " rozainee@fkkksa.utm.my, ${ }^{*}$ jamesoontl@hotmail.com
}

\begin{abstract}
Dried fish is commonly produced by convective hot air drying. Microwave technology was presented in this paper to improve both process and product quality. Catfish (order Siluriformes) slices were dehydrated in a microwave assisted hot air convective dehydration (MWHA) system to investigate the effects of microwave power and hot air temperature on drying time, dehydration behaviour, energy consumption and colour of dried fish. Three different microwave power outputs namely medium (373 $\mathrm{W})$, medium low $\left(217 \mathrm{~W}\right.$ ) and low $(91 \mathrm{~W})$ combined with convective hot air temperature of $40{ }^{\circ} \mathrm{C}, 70^{\circ} \mathrm{C}$ and $130{ }^{\circ} \mathrm{C}$ accordingly were employed in the drying experiments. Results show that microwave accelerates drying time up to 120 folds faster compared to drying with hot air convective alone. It was also noted that increasing the hot air temperature was not as significant as increasing the microwave power in reducing the drying time. Experiments show that drying time was reduced about $75 \%$ when an increase of microwave power from low $(91 \mathrm{~W}$ ) to medium mode (373 W) combining with convective hot air. However, drying with microwave alone required longer drying time. Energy consumption analysis shows that microwave assisted drying process requires less energy usage. Drying fish with microwave assisted hot air dehydration treatment make the colour brighter, shifting towards red and yellow.
\end{abstract}

Keywords - microwave, fish slice, dehydration, drying characteristic, energy aspects, colour assessment.

\section{INTRODUCTION}

Drying is one of the methods to preserve fish. Dried fish can be stored for several years due to the reduced water activity. Dried fish usually consumed after further cooking. It can be also send to further process and packed as snack food. Current fish processing industry uses convective hot air or sun drying to produce dried fish. Several concerns integrated with these methods are time consuming, poor sanitary handling during processing, non-sterilisation, poor quality and non-attractive appearance of finished product.

Microwave assisted hot air convective dehydration (MWHA) system which presented in this paper is a combination drying technology of microwave and convective hot air. Microwaves are electromagnetic waves in the frequency range of $300 \mathrm{MHz}$ to $300 \mathrm{GHz}$, generated by a magnetron tube. In the industry, frequency of $2450 \mathrm{MHz}$ is widely applied for heating and drying purposes. Microwave heating is volumetric due to penetration of microwave within drying material and dielectric effect. It is different than conventional drying methods which normally energy is transferred from surface of material into interior during conventional drying. Thus, microwave provides fast and uniform heating throughout the entire product.

Zhang et al. has summarized the combined microwave related drying applications together with their pros and cons [1]. MWHA system is one of the popular technologies among the discussion. During drying, microwave energy heats up and evaporates moisture content while forced air is supplied to carry away water vapour. It is noted that heated air has a bigger moisture carrying capacity [2].

Vast of materials have been successfully dried by MWHA technology: banana, American ginseng, peeled longan, spinach, garlic and other agricultural produces [2][6]. However, little is available of MWHA on fish material. The objectives of the present work were to: (1) discuss the influence of microwave power and hot air temperature on drying characteristics; (2) compare the effectiveness of microwave hot air combination drying with convective hot air dying in term of energy consumption and colour of finished product. 


\section{MATERIALS AND METHODS}

\section{A. Drying System}

MWHA was conducted with a Sharp microwave oven model R-958A (Japan) which has maximum power output of $900 \mathrm{~W}$ at $2450 \mathrm{MHz}$. Three modes of microwave power used in this research were medium, medium low and low, with the power output of $373 \mathrm{~W}, 217 \mathrm{~W}$ and $91 \mathrm{~W}$ respectively. The differences of each mode are: medium mode operates for 25 seconds and pauses for 20 seconds; medium low mode operates for 16 seconds and pauses for 29 seconds; low mode operates for 8 seconds and pauses for 37 seconds. The cycle period for each mode is 45 seconds. Hot air with different preset temperature was supplied through out the whole drying process. Meanwhile, hot air drying was conducted with same microwave oven by only apply convective hot air function.

\section{B. Microwave power output measurement}

The microwave power output in the microwave oven was determined calorimetrically [7].

\section{Experimental Procedure}

Fresh catfish (order Siluriformes) were obtained from aquaculture farm at Kampung Sinaran Baru, Skudai, Johor. The fish was headed and gutted, cut into pieces with average weight of $25.0 \pm 1.0 \mathrm{~g}$. Fish slices were brined in warm solution $(5 \% \mathrm{w} / \mathrm{v} \mathrm{NaCl})$ for 20 minutes. It was noted that ratio of brine solution to fish slices is 4 to 1 . After brining, fish slices were air dried for 5 minutes before putting into microwave oven.

MWHA was carried out at constant microwave output of $373 \mathrm{~W}$ (medium) coupled with hot air temperature of $40{ }^{\circ} \mathrm{C}, 70{ }^{\circ} \mathrm{C}$ and $130{ }^{\circ} \mathrm{C}$ respectively until desired moisture content achieved $(0.1 \mathrm{~kg} / \mathrm{kg}$ d.b.). Experiments were repeated with microwave output of 217W (medium low) and $91 \mathrm{~W}$ (low) coupled with three hot air temperature levels mentioned correspondingly. All of total nine different experiment designs were carried out. Weights of fish slices were recorded for every 45 seconds, once a cycle period of microwave drying was completed.

Besides, experiments were also conducted with only applying microwave power output of 373W (medium) and 217W (medium low) respectively without convective hot air.

For convective hot air drying alone, temperature of $70{ }^{\circ} \mathrm{C}$ was applied. Weights of fish slices were recorded for every hour.

\section{Colour Parameters}

Colour of dried fish slices were determined by a Minolta Chroma CR-10 colorimeter (Japan). Three random readings for each selected sample were recorded. Average values of colour parameters of brightness coordinate $\mathrm{L}^{*}$, chromaticity coordinate $a^{*}$ and coordinate $b^{*}$ with standard deviation values were reported.

\section{E. Specific Energy Consumption}

Energy consumption was recorded by connecting an Elcontrol nanovip power meter (Italy) to power supply of microwave oven. Specific energy consumption (SEC) of drying was expressed in $\mathrm{MJ} / \mathrm{kg}$ water evaporated, with the equation:

$$
S E C=\frac{\text { Energy Consumed }}{\text { Water Evaporated }}
$$

\section{RESULTS AND DISCUSSION}

\section{A. Dehydration Characteristic}

The effect of microwave power output on dehydration time of the fish slice samples was shown in Figure 1. Total drying time for the fish samples at medium, medium low and low microwave power mode coupled with convective hot air of $70{ }^{\circ} \mathrm{C}$ were 5,9 and 18 minutes respectively. It was observed that higher microwave power output improved drying rate. The drying time was reduced about 71-75 \% when an increase of microwave power output from low $(91 \mathrm{~W})$ to medium mode (373 W) coupled with convective hot air of $70{ }^{\circ} \mathrm{C}$. Similar findings were reported by Ozkan et al. and Karaaslan and Tuncer on spinach drying and Soysal on parsley drying[6]-[9].

Figure 2 shows the dehydration characteristics of fish slice sample by convective hot air $70{ }^{\circ} \mathrm{C}$. The drying process took 10 hours to achieve desired moisture content $(0.1 \mathrm{~kg} / \mathrm{kg}$ d.b.). The drying rate was 120 times slower compared to the highest microwave mode applied in this research. The slow drying rate was attributed to surface heating by convective hot air. According to Mujumdar, two processes will occur simultaneously when wet material subjected to thermal drying: first, transfer of energy from surrounding environment evaporates surface moisture and; second, internal moisture transfer from the material to surface and subsequently evaporate as happening in first process[10]. Thus, mass transfer of conventional drying is solely due to mass concentration gradient existing between wet interior and drier surface and this is always a slow process [11]. However, microwave assisted drying method supplies energy to generate heat internally within the materials due to dielectric property, contribute to volumetric heating. Furthermore, mass transfer in microwave assisted drying primarily governed by total pressure gradient established due to rapid generation of vapour within the material. Therefore, fast drying occurs.

The effect of convective hot air on the dehydration time of the fish slice samples coupled with microwave power output of medium (373W) and low (91W) were shown in Figure 3 and Figure 4 respectively. The drying time for medium microwave power mode coupled with convective hot air of $40{ }^{\circ} \mathrm{C}, 70{ }^{\circ} \mathrm{C}, 130{ }^{\circ} \mathrm{C}$ were $5,5,6$ minutes respectively. It was observed that higher temperature of convective hot air did not supply on fast drying. Nevertheless, the drying time for low microwave power mode coupled with convective hot air of $40{ }^{\circ} \mathrm{C}$, $70{ }^{\circ} \mathrm{C}, 130{ }^{\circ} \mathrm{C}$ were 21,18 and 16 minutes respectively. This may be explained that the increase of hot air temperature 
was more significant when lower microwave power level applied.

Overall, the hot air temperature was less significant in reducing drying time compared with varying the microwave power. Andrés et al and Varith et al. reported similar findings on apple and peeled longan drying respectively [5],[12].

However, convective hot air is important to play the role as the moisture carrier [13]. The heated convective air is useful in the drying process for creating an unsaturated ambient condition and increasing its moisture capacity [14]. The important of convective hot air was illustrated in Figure 3 where the microwave drying without coupled with convective hot air required longer drying time to achieve the same desired moisture content compared to those coupled with convective hot air.

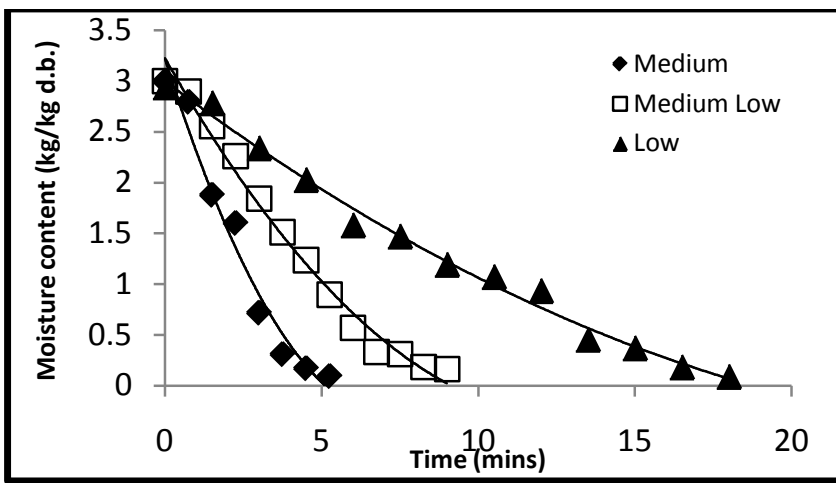

Figure 1: Effect of microwave power output of Medium (373W), Medium Low (217W) and Low (91W) on the drying time with convective hot air temperature of $70^{\circ} \mathrm{C}$.

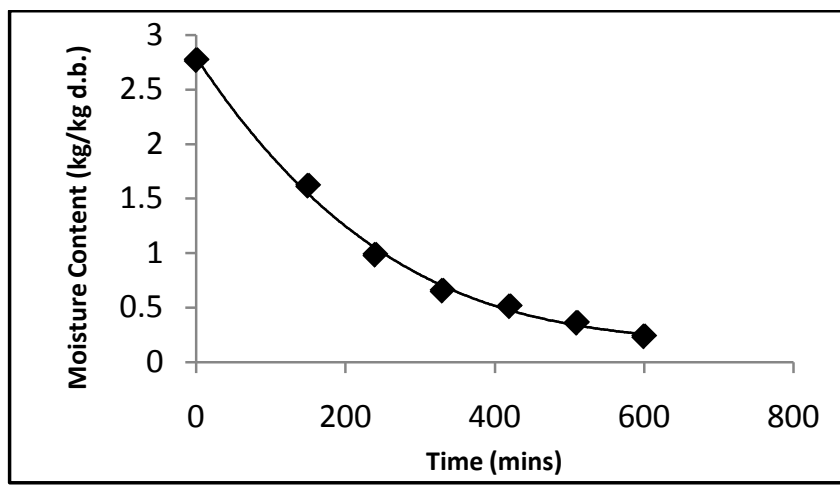

Figure 2: Dehydration characteristics of fish slice sample by convective hot air drying of $70^{\circ} \mathrm{C}$.

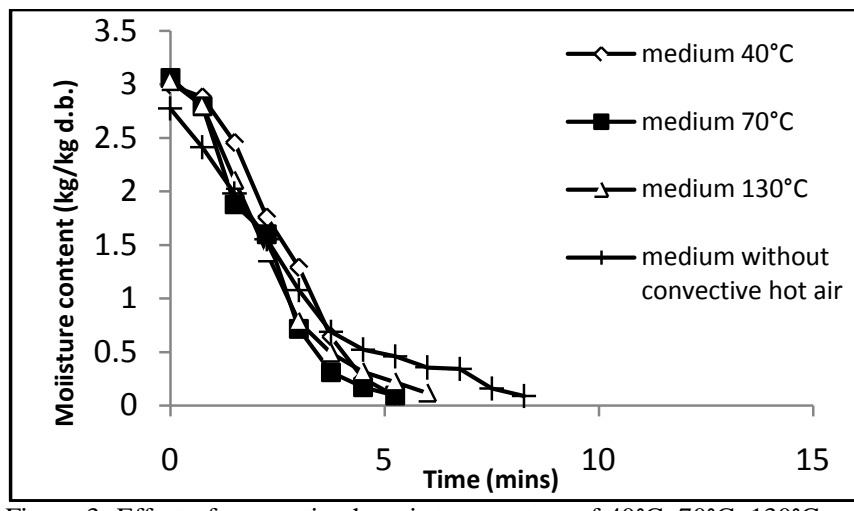

Figure 3: Effect of convective hot air temperature of $40^{\circ} \mathrm{C}, 70^{\circ} \mathrm{C}, 130^{\circ} \mathrm{C}$ and without hot air on the drying time at medium (373W) microwave power.

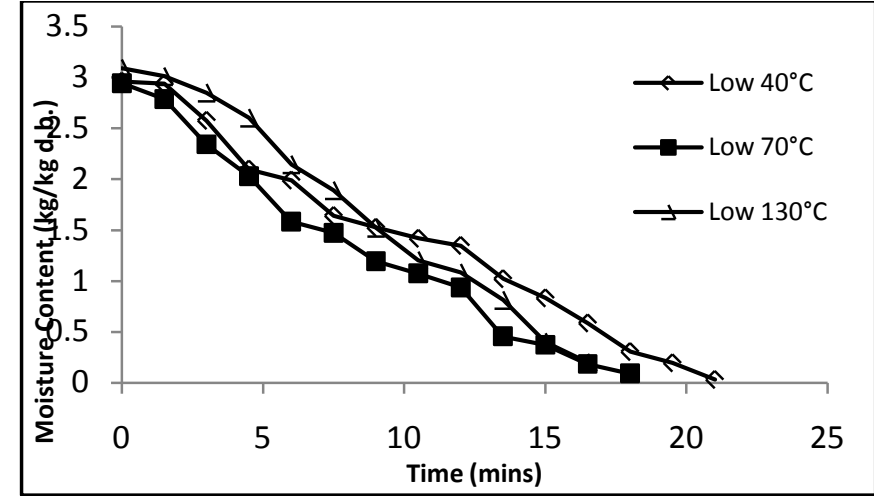

Figure 4:Effect of convective hot air temperature of $40^{\circ} \mathrm{C}, 70^{\circ} \mathrm{C}$ and $130^{\circ} \mathrm{C}$ on the drying time at Low $(91 \mathrm{~W})$ microwave power.

\section{B. Colour Analysis and Energy Consumption Measurement}

Table 1 shows the result of the colour measurements of dried fish slices. It was observed that the brightness parameter $\left(\mathrm{L}^{*}\right)$ for the sample dried by convective hot air alone was lower than other treatments, which indicated the darkest among the dried product. On the other hand, the fish slices dried by combination of low microwave power and convective hot air has the highest value in redness parameter $\left(\mathrm{a}^{*}\right)$ while the combination of medium microwave power and convective hot air at $130{ }^{\circ} \mathrm{C}$ gave the highest value in yellowness parameter ( $\left.b^{*}\right)$. For overall, Drying fish with microwave assisted hot air dehydration treatment make the colour brighter, shifting towards red and yellow.

The specific energy consumption of various drying conditions was presented in Figure 5. It was observed that specific energy consumption reduced drastically during MWHA. Energy consumption of convective hot air drying of $70^{\circ} \mathrm{C}$ was $164.3 \mathrm{MJ} / \mathrm{kg}$ of water removed, whereas MWHA dehydration with low (91W), medium low (217W) and medium (373W) mode of microwave power coupled with hot air temperature of $70^{\circ} \mathrm{C}$ required only $15.7 \mathrm{MJ} / \mathrm{kg}$, $33.0 \mathrm{MJ} / \mathrm{kg}$ and $27.7 \mathrm{MJ} / \mathrm{kg}$ respectively. This indicated saving of $90.4 \%, 79.9 \%$ and $83.2 \%$ accordingly in energy consumption. The result was in the agreement with Varith et al. on peeled longan drying [5]. Although microwave operation required higher energy supply, shorter drying time of microwave assisted dehydration contribute to less energy consumption. It was noted that the comparison is valid since same dryer was used for both convective hot air drying and microwave assisted drying [14]. 
Table 1: Effect of Microwave Power and Convective Hot Air Temperature on Colour Parameters of Fish Slice Samples

\begin{tabular}{|c|c|c|c|c|c|c|c|}
\hline \multirow{2}{*}{ Drying Method } & \multirow{2}{*}{$\begin{array}{l}\text { Drying } \\
\text { time } \\
\text { (mins) }\end{array}$} & \multicolumn{6}{|c|}{ Colour Parameters } \\
\hline & & \multicolumn{2}{|l|}{$\mathrm{L}^{*}$} & \multicolumn{2}{|l|}{$\mathrm{a}^{*}$} & \multicolumn{2}{|l|}{$\mathrm{b}^{*}$} \\
\hline Convective hot air, ${ }^{\circ} \mathrm{C}$ & & & & & & & \\
\hline 70 & 600 & 40.9 & $(0.8962)$ & 4.1 & $(0.2309)$ & 13.9 & $(0.8962)$ \\
\hline Microwave power & & & & & & & \\
\hline Medium Low (217W) & 16 & 47.9 & $(0.1154)$ & 5.3 & $(0.0577)$ & 21.2 & $(0.0999)$ \\
\hline Microwave power + Convective & & & & & & & \\
\hline Low $(91 \mathrm{~W})+40^{\circ} \mathrm{C}$ & 21 & 51.8 & (1.6703) & 10.3 & $(0.9865)$ & 27.1 & $(0.3785)$ \\
\hline Low $(91 \mathrm{~W})+130^{\circ} \mathrm{C}$ & 17 & 49.5 & (3.9837) & 12.4 & $(0.6999)$ & 27.8 & $(2.3437)$ \\
\hline Medium Low $(217 \mathrm{~W})+40^{\circ} \mathrm{C}$ & 6 & 45.3 & $(1.2503)$ & 8.0 & $(0.2516)$ & 21.3 & $(1.0440)$ \\
\hline Medium Low $(217 \mathrm{~W})+130^{\circ} \mathrm{C}$ & 8 & 48.2 & $(1.0583)$ & 9.7 & $(1.3613)$ & 24.6 & $(0.6110)$ \\
\hline Medium $(373 \mathrm{~W})+40^{\circ} \mathrm{C}$ & 5 & 53.1 & $(1.0969)$ & 7.1 & $(0.1999)$ & 25.0 & (1.8448) \\
\hline Medium $(373 W)+130^{\circ} \mathrm{C}$ & 6 & 58.7 & (1.7214) & 6.8 & $(0.1527)$ & 28.2 & $(0.5686)$ \\
\hline
\end{tabular}

Note: Each data represent mean of three replications with standard error.

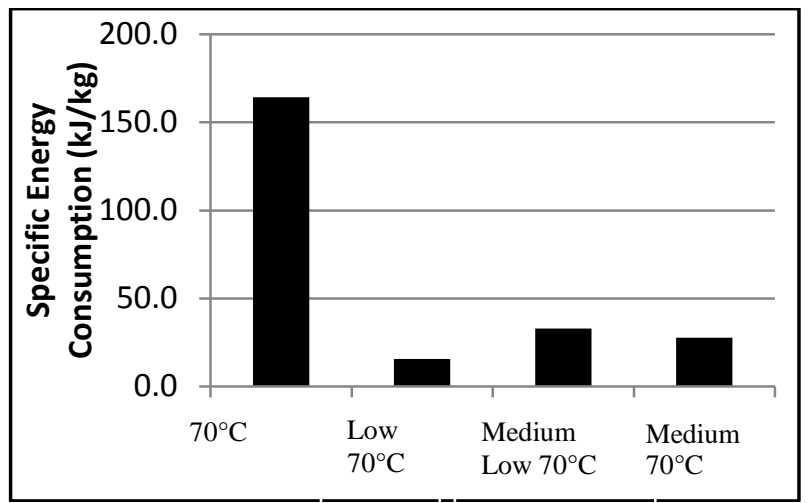

Figure 5:Specific energy consumption of drying with microwave power output of Medium (373W), Medium Low (217W), Low (91W)and without microwave assisted coupled with convective hot air temperature of $70^{\circ} \mathrm{C}$.

\section{CONCLUSIONS}

Drying of fish slices using medium microwave power mode coupled with hot air temperature of $70^{\circ} \mathrm{C}$ was 120 folds faster than the conventional drying method. It was observed that increasing of hot air temperature was not as significant as increasing the microwave power in reducing the drying time. However, the present of convective hot air was important which plays the role as moisture carrier in the microwave drying process. For quality analysis, Drying fish with microwave assisted hot air dehydration treatment make the colour brighter, shifting towards red and yellow. Furthermore, microwave assisted dehydration saving about $80 \%$ to $90 \%$ compared to convective hot air drying.

\section{NOMENCLATURE}

* $\quad$ colour coordinate, redness (+)/ greenness (-), dimensionless

b* colour coordinate, yellowness $(+) /$ blueness $(-)$, dimensionless

L* colour whiteness coordinate, darkness (0)/ brightness (100)

SEC specific energy consumption

\section{REFERENCES}

[1] M. Zhang, J. Tang, A. S. Mujumdar, \& S. Wang, "Trends in microwave-related drying of fruits and vegetables," Trends in Food Science and Technology, vol. 17, pp. 524-534, 2006.

[2] S. P. Sharma, S. Prasad, \& V. K. Chabar, "Moisture transport in garlic cloves undergoing microwave convective drying," Food and Bioproduct Processing, vol. 87, pp. 11-16, 2009.

[3] M. Maskan, "Microwave/Air and microwave finish drying of banana," Journal of Food Engineering, vol. 44, pp. 71-78, 2000.

[4] G. Ren, \& F. Chen, "Drying of American Ginseng (Panax quinquefolium) Roots by Microwave hot air combination,” Journal of Food Engineering, vol. 35, pp. 433-443, 1998.

[5] J. Varith, P. Dijkaranurukkul, A. Achariyaviriya, \& S. Achariyaviriya, "Combined microwave-hot air drying of peeled loangan," Journal of Food Engineering, vol. 81, pp. 459-498, 2007.

[6] S. N. Karaaslan, \& I. K. Tuncer, "Development of a drying model for combined-fan-assisted convection drying of spinach," Biosystems Engineering, vol. 100, pp. 44-52, 2008.

[7] M. A. M. Kharausheh, W. A. M. McMinn and T. R. A. Magee, "Quality and Strutural Changes in Starchy Foods during Microwave and Convective Drying," Food Research International, vol. 37, pp. 497-503, 2004.

[8] I. A. Ozkan, B. Akbudak, \& N. Akbudak, "Microwave drying characteristics of spinach," Journal of Food Engineering, vol. 78, pp. 577-583, 2007.

[9] Y. Soysal, "Microwave Drying Characteristics of Parsley,” Biosystems Engineering, vol. 89(2), pp. 167-173, 2004.

[10] A. S. Mujumdar, Handbook of Industrial Drying: Principle, Classification and Selection of Dryers, $3^{\text {rd }}$ ed., Baco Raton, 2007.

[11] R. F. Schiffmann, Handbook of Industrial Drying: Microwave and Dielectric Drying, ${ }^{\text {rd }}$ ed., Mujumdar, A., S., Ed., Baco Raton, 2007.

[12] A. Andrés, C. Bilbao, \& P. Fito, "Drying kinetics of apple cylinders under combined hot air-microwave dehydration," Journal of Food Engineering, vol. 63, pp. 71-78, 2004.

[13] E. C. M. Sanga, A. S. Mujumdar, \& G. S. V. Raghaven, "Simulation of convection-microwave drying for a shrinking material," Chemical Engineering and Processing, vol. 41, pp. 487-499, 2004.

[14] G. P. Sharma, \& S. Prasad, "Specific energy consumption in microwave drying of garlic cloves,” Energy, vol. 31, pp. 1921-1926, 2006. 